\title{
KLASIFIKASI OPINI GREEN AND CLEAN KABUPATEN LAMONGAN MENGGUNAKAN ALGORITMA MULTINOMIAL NAIVE BAYES
}

\author{
Agus Setia Budi \\ Dosen Program Studi Teknik Informatika, Fakultas Teknik, Universitas Islam Lamongan \\ Jl. Veteran No. 53 A Lamongan \\ Telp. (0322)324706 \\ Email:geniusbudi@yahoo.com
}

\begin{abstract}
This study aims to process and classify an opinion (Opinion mining), opinion is a subjective statement that reflects public sentiment or perception of the entity or activity. Most opinions has not been managed well, if The Opinions properly managed will provide important information can be used to make improvements toward better at an activity or program. This study focuses on the processing of opinions that come from public opinion In Lamongan against LGC program which includes cleanliness, green and financial. The study was divided into two phases, namely the training process to produce data (dataset) to perform the classification process and the subjective (datates). Both processes are aimed to extract attributes and object components that have been commented upon in any document and to determine whether positive or negative comments. The results of the subjective test classification using Multinomial Naive Bayes algorithm has a success rate above $80 \%$ classification accuracy when it is matched with the manual classification.
\end{abstract}

Key Words: Opinion, Opinion Mining, Multinomial Naive Bayes

\section{PENDAHULUAN}

Pada saat ini pengklasifikasian dilakukan secara manual oleh staf BLH, namun dengan semakin banyaknya opini yang harus diproses maka waktu yang dibutuhkan akan semakin lama dan tingkat akurasi juga semakin berkurang dikarenakan keterbatasan kemampuan manusia dalam memproses data. Ide untuk membuat aplikasi opini secara elektronikpun sudah dilakukan yakni aplikasi opini, namun ide ini masih belum efektif dan belum akurat dikarenakan masyarakat terkadang belum mengarah ke tujuan yang sesuai dengan opini yang disampaikan. Dari permasalahan diatas maka disiplin ilmu teks mining menjadi tolak metode penting yang dimanfaatkan pada penelitian ini. Teks mining memiliki definisi menambang data yang berupa teks dimana sumber data dapat mewakili isi dari dokumen. Metode yang digunakan dalam pengklasifikasian ini adalah Multinomial Naïve Bayes.

Langkah yang akan di ambil pada penelitian nantinya berawal dari memasukkan informasi berupa data opini dari sistem opini kemudian dilakukan preprocessing terhadap kumpulan opini tersebut, kemudian setelah preprocessing tersebut dilakukan, selanjutnya dilakukan proses pembobotan term dengan algoritma Nazied and andriani, hasilnya akan menjadi bahan training dan pada akhirnya akan dilakukan perhitungan dengan Multinomial Naïve Bayes untuk penentuan klasifikasi.

Program LGC di Lamongan telah berjalan selama 6 tahun. Selama ini dalam mengevaluasi tujuan program LGC hanya berdasarkan pada sudut pandang pimpinan daerah, kepala BLH dan karyawan tanpa melibatkan komponen yang sebenarnya merupakan objek dari program LGC itu sendiri yaitu warga atau masyarakat.

\section{METODE PENELITIAN}

Proses Klasifikasi Data Opini adalah proses klasifikasi data yang diambil dari data opini. Bisa dilihat pada flowchart sistem untuk proses data uji coba opini, perhatikan gambar 1 di bawah ini.

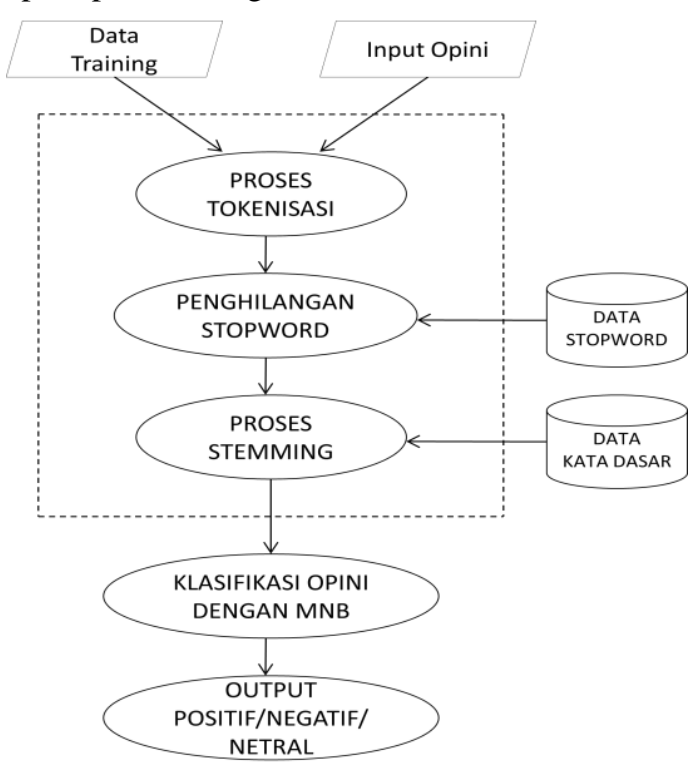

Gambar 1. Flowchat Data Training dan Klasifikasi Opini

Pada metode penelitian Metode Multinomial Naïve Bayes diharapkan dapat membantu penanggung jawab program Badan Lingkungan Hidup (BLH) dan Bupati Lamongan untuk mengetahui opini masyarakat terhadap program LGC, dengan tingkat akurasi ketepatan klasifikasi $80 \%$ bila dicocokkan dengan hasil klasifikasi manual.

- Arsitektur sistem dataset atau data training 


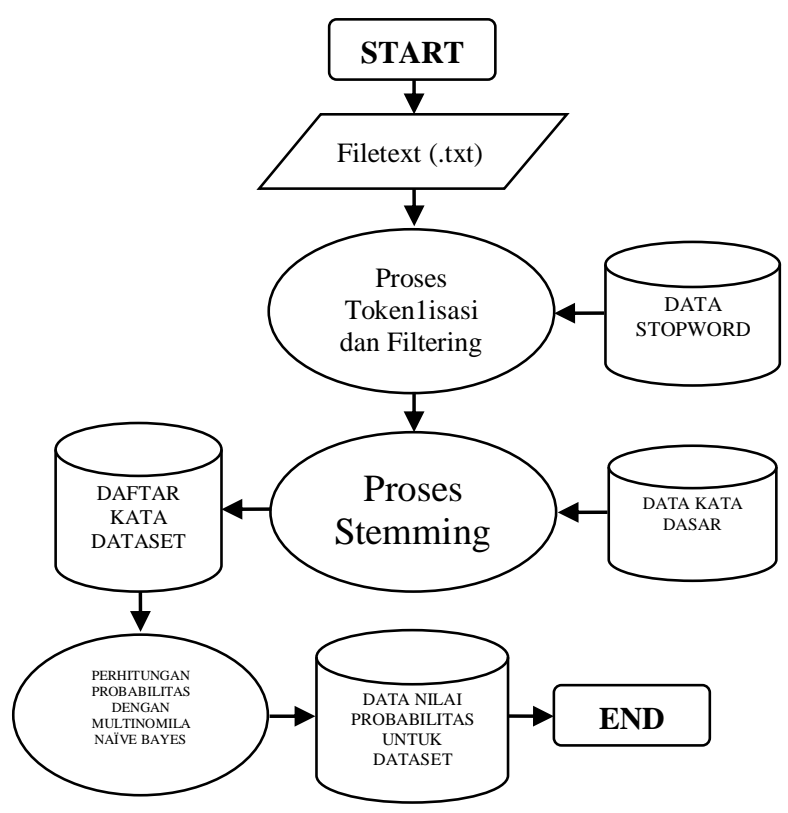

Gambar 2. Arsitektur Sistem Dataset Untuk Klasifikasi Opini

- Arsitektur sistem datates

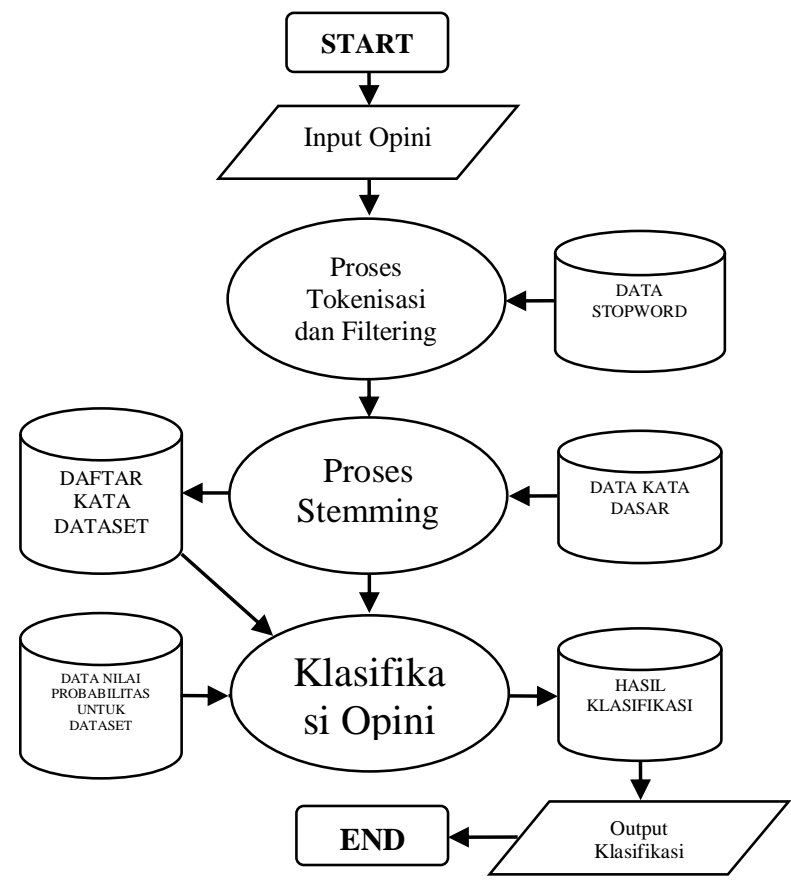

Gambar 3. Arsitektur Sistem Datates Untuk Klasifikasi Opini

\section{HASIL DAN PEMBAHASAN}

Desain interface merupakan rancangan desain antar muka antara sistem dengan pengguna, desain ini meliputi :

a. Desain interface untuk entri data data training secara manual. desain ini digunakan untuk memasukkan data training dengan cara mengetikkan data kuisoner secara langsung tidak melalui file text. Untuk lebih jelasnya bisa lihat pada gambar 4. di bawah ini.

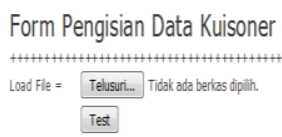

Gambar 4. Desain Interface Entri Data Training Secara Manual

Proses tokenisasi, penghapusan stopword dan stemming. Data training harus diinputkan kedalam system. Jika file kosong maka ada umpan balik kepada user bahwa data kosong kalau sudah benar memulai teks sama dengan teks dan akan menjadikan huruf kecil token karakter sama dengan pemisah antar kata dengan symbol, lalu di proses token, proses penghapusan stopword dan selanjutnya tampungan hasil dari proses token dan removal stopword.

Desain interface untuk entri data data training secara manual. desain ini digunakan untuk memasukkan data training dengan cara mengetikkan data kuisoner secara langsung tidak melalui file text. Untuk lebih jelasnya bisa lihat pada gambar 5. di bawah ini.

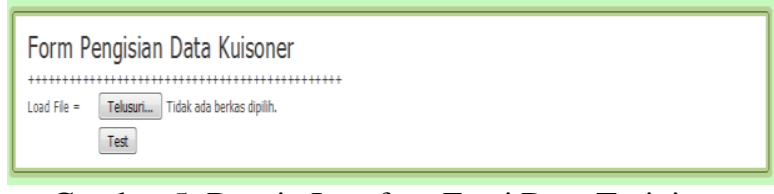

Gambar 5. Desain Interface Entri Data Training Secara Manual

Desain interface untuk input opini. Untuk lebih jelasnya bisa lihat pada gambar 6 . di bawah ini.

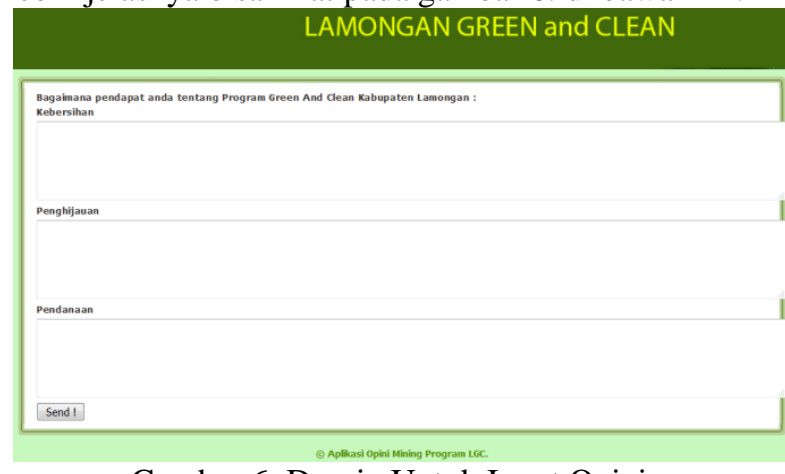

Gambar 6. Desain Untuk Input Opini

Algoritma entri data untuk data training, proses untuk menghasilkan data training file tidak boleh kosong, jika file masih kosong ada kata data masih kosong. Disini kalau sudah benar dan sudah tidak kosong. Mulai memanggil fungsi token untuk memisah kata lalu memanggil fungsi remove stopword untuk menghapus stopword atau kata sambung lalu mencari kata dasar sebuah kata proses stemming.

Berikut ini diberikan beberapa sebuah contoh kalimat opini yang sebelumnya tidak terdapat kata hedge, kemudian dibandingkan dengan kata yang didalamnya terdapat kata hedge.

Contoh Inputan Opini yang Bernilai Positif

kebersihan lingkungan warga terjaga dengan baik 
penghijauan di lamongan sangat baik

biaya sangat murah sekali

Maka hasil yang diperoleh pada inputan opini yang bernilai positif, bisa dilihat pada gambar 7. di bawah.

\begin{tabular}{|l|l|}
\hline Kebersihan lingkungan warga terjaga dengan baik & Bersih Positif \\
\hline penghijijuan di lamongan sangat bajk & Penghijauan Positif \\
\hline biaya sangat murah sekali & Pendanaan Positiff \\
\hline
\end{tabular}

Gambar 7. Contoh Hasil Klasifikasi Opini yang Bernilai Positif

Untuk melakukan verifikasi hasil percobaan, dilakukan percobaan sebanyak $10 \mathrm{kali}$, dataset dari percobaan ini di bagi menjadi dua yakni data latih dan data testing, penentuan data latih dan data testing ini dilakukan secara acak dan merata agar tidak terjadi pengelompokan dokumen-dokumen yang berasal satu kategori tertentu pada sebuah percobaan, data latih di ambil sebanyak $70 \%$ dari dataset secara acak dan merata untuk setiap kategori, sedangkan sisanya dipakai sebagai data testing, pembagian data ini akan dilakukan sebanyak 10 kali untuk sepuluh percobaan. Hasil confution matrik uji coba dari percobaan nantinya di cari nilai akurasi rata-rata. Hasil dari confution matrix uji coba terbaik ditunjukkan pada Gambar 8.

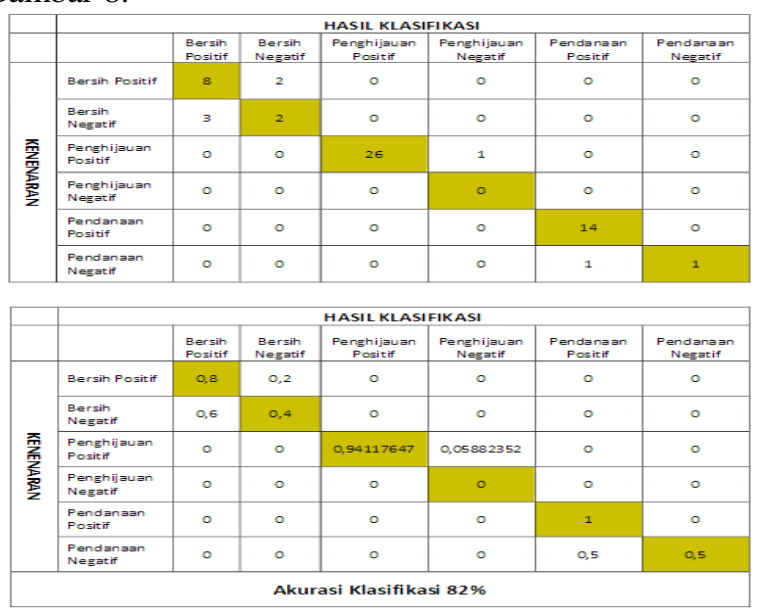

Gambar 8. Hasil Uji Coba Matrix

Proses Penentuan jenis data untuk data uji dilakukan dengan memilih jumlah data uji yang akan diklasifikasi, ditunjukkan pada gambar 9.

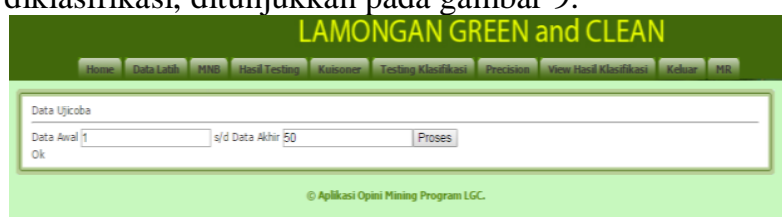

Gambar 9. Form Untuk Tes Klasifikasi Data Uji

Setelah proses segmentasi ada beberapa proses yang harus dilakukan sebelum melakukan ektraksi ciri daiantranya proses delasi, erosi, skeletoning dan pelabelan, untuk hasil uji coba ektraksi ciri menggunakan invarian moment dapat dilihat pada tabel 2. sedang untuk hasil uji coba ektraksi ciri menggunakan morfologi dapat dilihat pada tabel 3 . berikut ini:

Dari beberapa uji coba terbaik maka bisa di buat tabel data cross validation dan bisa ditunjukkan pada hasil cross validation, pada tabel 2 .

Tabel 2. Data Cross Validation Fold $=10$

\begin{tabular}{|l|c|c|c|c|c|c|c|c|c|c|}
\hline Latih Ke & $\mathbf{1}$ & $\mathbf{2}$ & $\mathbf{3}$ & $\mathbf{4}$ & $\mathbf{5}$ & $\mathbf{6}$ & $\mathbf{7}$ & $\mathbf{8}$ & $\mathbf{9}$ & $\mathbf{1 0}$ \\
\hline Dok Awal & 1 & 51 & 101 & 151 & 201 & 251 & 301 & 351 & 401 & 451 \\
\hline Dok Akhir & 50 & 100 & 150 & 200 & 250 & 300 & 350 & 400 & 450 & 500 \\
\hline $\begin{array}{l}\text { Hasil } \\
\text { Prosentase }\end{array}$ & $82 \%$ & $88 \%$ & $84 \%$ & $90 \%$ & $88 \%$ & $86 \%$ & $82 \%$ & $78 \%$ & $72 \%$ & $76 \%$ \\
\hline & & & & & & & & Rata2 & $\mathbf{8 3} \%$ \\
\hline
\end{tabular}

Pada tabel 2. ditunjukkan nilai akurasi terbesar terjadi pada percobaan ke 4 dengan nilai $90 \%$ sedangkan rata-rata akurasi yang terjadi adalah $83 \%$.

Gambar 10. berikut ini merupakan hasil hasil perhitungan confution matrix terhadap percobaan terbaik.

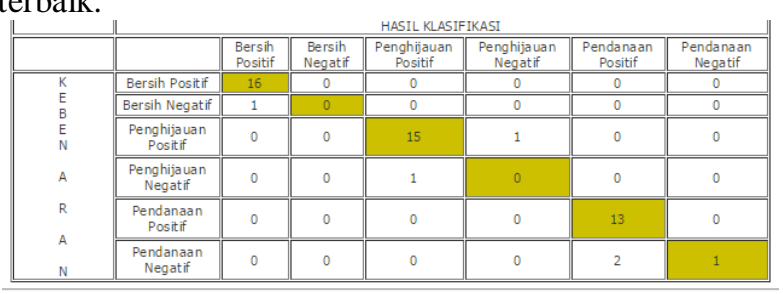

Cofution Matrix

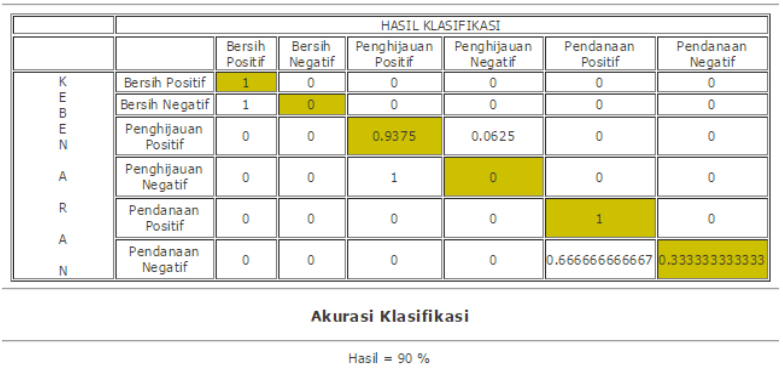

Gambar 10. Hasil Confution Matrix Uji Coba Terbaik

Dari confution matrix uji coba terbaik di dapat hasil dan dilakukan perhitungan nilai akurasi sebagai berikut :

Untuk menghitung akurasi data digunakan rumus

Akurasi $=\frac{\text { Jumlah klasifikasi secara benar }}{\text { Jumlah semua data klasifikasi }}$

$\begin{array}{ll}\text { Akurasi } & =\frac{172}{200} \\ \text { Akurasi } & =0.83 \text { atau } 83,00 \%\end{array}$

Dari perhitungan nilai akurasi berdasarkan confution matrix didapatkan akurasi klasifikasi ratarata sebesar $83 \%$. Dengan demikian akurasi klasifikasi opini dengan metode multinomial naive bayes memperoleh hasil yang bagus.

\section{KESIMPULAN}

Adapun beberapa kesimpulan yang didapatkan antara lain:

1. Data hasil percobaan yang dilakukan untuk mengklasifikasi data opini masyarakat menggunakan multinomial naïve bayes yang diusulkan terbukti mampu melakukan klasifikasi dokumen opini masyarakat. 
2. Dengan menggunakan metode klasifikasi teks, dari segi kecocokan jenis kelas yang dihasilkan klasifikasi terhadap penentuan jenis kelas yang dilakukan oleh petugas BLH (Badan Lingkungan Hidup) tergolong baik, presentasi kecocokan kelas terhadap 200 data uji rata-rata sebesar $83 \%$.

3. Dengan menggunakan metode klasifikasi teks yaitu metode multinomial naïve bayes, dengan penentuan jenis kelas yang dilakukan oleh petugas BLH tergolong baik, Hasil klasifikasi bila dibanding dengan hipotesa yang diambil, maka sistem ini telah berjalan dengan baik. Terbukti dengan akurasi mencapai $83 \%$

4. Dengan pengklasifikasian data opini masyarakat dengan metode Multinomial Naïve Bayes dapat memudahkan pimpinan dalam melakukan evaluasi program LGC di Lamongan.

\section{REFERENSI}

[1] Alexander Pak, Patrick Paroubek “ Twitter as a Corpus for Sentiment Analysis and Opinion Mining “, Universit”e de Paris-Sud, Laboratoire LIMSI-CNRS, B`atiment 508
[2] Bing Liu, "Opinion Mining”, Department of Computer Science University of Illinois at Chicago.

[3] Destuardi, Surya Sumpeno (2009), "Klasifikasi Emosi Untuk Teks Bahasa Indonesia Menggunakan Metode Naive Bayes", Jurusan Teknik Elektro, Institut Teknologi Sepuluh Nopember Kampus ITS, Sukolilo, Surabaya 6011.

[4] Erik Boiy; Pieter Hens; Koen Deschacht; MarieFrancine Moens, "Automatic Sentiment Analysis in On-line Text, Katholieke Universiteit Leuven, Tiensestraat 41 B-3000 Leuven, Belgium

[5] Jais Hardinal, Bayu Distiawan Trisedya, (2009), "Klasifikasi Dokumen Menggunakan Algoritma Naïve Bayes dengan Penambahan Parameter Probabilitas Parent Category", Fakultas Ilmu Komputer Universitas Indonesia.

[6] S.L. Ting; W.H. Ip; Albert H.C. Tsang “ Is Nä̈ve Bayes a Good Classifier for Document Classification? " International Journal of Software Engineering and Its Application Vol.5, No. 3, University Hung Hum, Kowloon, Hongkong 2011 